\title{
SOBRE LAS DIFICULTADES QUE GENERA LA COMPRENSIÓN DE LAS POSIBILIDADES Y EXTENSIÓN DEL INTERROGATORIO JUDICIAL EN EL MARCO DE UN PROCESO PENAL ACUSATORIO-ADVERSARIAL ${ }^{*}$
}

\section{Diego Palomo Vélez ${ }^{* *}$}

Santiago, primero de septiembre de dos mil nueve.

\section{VISTOS:}

Por resolución de tres de junio del presente año, extendida en la causa RUC N 0710026300-3, RIT N³3-2009, por el Tribunal de Juicio Oral en lo Penal de Chillán, integrado por los jueces titulares señor Gonzalo Bustos García, que lo presidió, así como por doña María Paz González González y don Oscar Ruiz Paredes, este último encargado de su redacción, se castigó a José Felizmer Rivas González, cédula de identidad $N^{\circ}$ 8.618.249-1, de cuarenta y nueve años de edad, casado, operador de maquinaria, domiciliado en Sector Confluencia s/n de Quinchamalí, a sufrir ocho ańos de presidio mayor en su grado mínimo, accesorias legales pertinentes y las que se especifican con arreglo al artículo 372 del Código Penal, así como a enterar las costas del pleito, por su responsabilidad de autor del delito consumado de violación de la menor Evelyn G.R.T., perpetrado en fecha indeterminada en el período comprendido entre noviembre de dos mil seis a diciembre de dos mil siete, en el sector Confluencia, localidad de Quinchamalí, comuna de Chillán.

En contra de este laudo, la abogada de la Defensoría Penal Pública, doña Gilda Martínez Alfaro, en representación del convicto Rivas González, dedujo de fojas 18 a 30, recurso de nulidad asilado en los artículos 373, letra a), y 374, letra e), del Código Procesal Penal, que interpone de manera subsidiaria.

Declarado admisible el arbitrio a fojas 39, se fijó día para la audiencia, la que tuvo lugar el doce de agosto recién pasado, una vez rendida la

Mis agradecimientos a Humberto Alarcón Corsi, Defensor Local Jefe de Concepción, profesor de Derecho Penal de la Universidad de Talca, y a Pelayo Vial Campos, Jefe de Estudios de la Defensoría Regional del Bíobío, por el material y comentarios compartidos para la elaboración de este texto.

** Profesor de Derecho Procesal de la Facultad de Ciencias Jurídicas de la Universidad de Talca (Chile). Director del Departamento de Derecho Penal, Procesal y del Trabajo. Doctor en Derecho por la Universidad Complutense de Madrid (España). Correo electrónico: dpalomo@utalca.cl 
prueba ofrecida en el otrosí de fojas 18 a 30 y oídos los intervinientes, se levantó el acta que rola a fojas 43, y quedaron los autos para fallo.

\section{CONSIDERANDO:}

PRIMERO: Que por el recurso entablado se han invocado en forma subsidiaria las causales de las letras a) del artículo 373 y e) del artículo 374 del Código Procesal Penal. Aquella -como principal-, referida al caso en que en cualquier fase del procedimiento o en el pronunciamiento de la sentencia, se hubieren conculcado sustancialmente derechos o garantías asegurados por la Constitución o por los tratados internacionales ratificados por Chile en vigencia; en tanto que por la otra -como subsidiaria-, cuando en la sentencia se hubiere omitido alguno de los requisitos del artículo 342, letra c), esto es, la exposición clara, lógica y completa de cada uno de los hechos y circunstancias que se dieren por probados, fueren ellos favorables o desfavorables al acusado, y de la valoración de los medios de prueba que fundamentaren dichas reflexiones de acuerdo con el artículo 297, referido a la valoración de los medios de prueba en que descansen sus conclusiones.

SEGUNDO: Que por lo que toca a la motivación principal del libelo en análisis, se denuncia la vulneración del debido proceso, constitucionalmente protegido en el artículo $19, \mathrm{No}^{\circ}$, inciso quinto, de la Carta Fundamental, y singularmente uno de sus requisitos mínimos, consistente en el derecho a ser juzgado por un tribunal imparcial, el que fue desconocido durante el desarrollo del juicio oral e influyó en lo resuelto, con quebrantamiento de los artículos $1^{\circ}, 4^{\circ}$, inciso segundo del $5^{\circ}$ y 19 , $\mathrm{N}^{\circ} 3^{\circ}$, incisos $4^{\circ}$ y $5^{\circ}$, de la Carta Magna, $1^{\circ}$ del Código Procesal Penal, 14.1 del Pacto Internacional de Derechos Civiles y Políticos, y el 8.1 de la Convención Americana de Derechos Humanos.

TERCERO: Que, en lo que concierne a la forma en que se produjo semejante inobservancia, se censura desde luego la interrogación efectuada a la víctima del ilícito, porque la magistrada Sra. González realizó una serie de preguntas sugestivas y de manera reiterada, citando en su recurso dos de ellas: "a)...y dijisté que cosa respecto de él (el papá)...que te habia hecho qué?, a lo que la menor responde que la habia violado; y b) ...o sea, tú dijiste que tu papá te habia forzado a tener relaciones sexuales con él?, a lo que la victima responde que sí"). Más adelante, idéntico reparo se dirige contra la misma actividad realizada por la ya mencionada jurisdicente, en relación a la perito sicóloga Mariela Arriagada Brito, y resalta tres preguntas, que fueron: 1.- "¿Cuándo se entrevistó con Ud. esta niñita ya se habia retractado de su denuncia, luego me imagino yo que la entrevista siguió en ese pie, de decir... de exculpar a quien habia culpado en un primer momento, si o no?, a lo que la perito contesta que si". 2.- "... y si bien le entendi, la retractación es parte de un proceso de quienes sufren estas experiencias de violenta- 
ción sexual? A lo que la perito respondió afirmativamente”; y 3.- “...entonces el resultado de los test, más los antecedentes, tanto de la carpeta de investigación como la del centro en que Ud. trabaja, la llevan a concluir que es muy probable que los hechos denunciados sean ciertos? Esa es su conclusión? La perito contesta que esa es su conclusión".

CUARTO: Que lo expuesto implicó en concepto de la recurrente que la referida jueza manifestara su dictamen sobre cuestión pendiente, lo que provocó una falta a su deber de neutralidad; y peor aún, tuvo consecuencias en el veredicto inculpatorio final, prueba de ello es que se indicó expresamente en el motivo $10^{\circ}$, letra i), que precisamente de la pericia efectuada por la sicóloga, se llegó a la conclusión que existe una alta probabilidad sobre la existencia de los ilícitos sexuales vivenciados por la informada.

En seguida y siempre en lo atinente a la misma causal principal esgrimida, como nueva manifestación de la contravención al debido proceso y en especial el derecho a ser juzgado por un tribunal ecuánime, destaca los tiempos de interrogación utilizados por la juez, los que superaron con largueza los manejados por los intervinientes, e implica que no se trató de preguntas aclaratorias sino que constituyeron nuevos interrogatorios, no autorizados por la ley.

QUINTO: Que se reprocha haber violentado el derecho del enjuiciado a ser juzgado por un tribunal imparcial, lo que se colige del actuar de la sentenciadora durante el proceso, y de la propia decisión que se fundamentó en virtud de la información obtenida de la perito a través de las preguntas efectuadas, por lo que pide anular la sentencia y el juicio oral, ordenando retrotraer la causa al estadio procesal respectiva, a fin que el tribunal no inhabilitado que corresponda disponga la realización de un nuevo juicio oral fijando día y hora al efecto.

SEXTO: Que en lo que atañe a la letra e) del artículo 374, en consonancia con el 342, letra c), y vinculados a su vez con el artículo 297, todos del Código Procesal Penal, al omitirse por el edicto recurrido una exposición clara, lógica y completa de cada uno de los hechos y circunstancias que se dieron por probados, fueren ellos favorables o desfavorables al imputado, así como de la valoración de los medios de prueba que soportan dichas conclusiones.

SÉPTIMO: Que la crítica se construye a partir de cuatro aspectos; uno, consistente en la defectuosa fundamentación respecto de la fecha de ocurrencia de los hechos establecidos, lo que queda graficado en el motivo $19^{\circ}$ de la resolución impugnada, en donde se sostiene que el hecho habría acontecido en: "fecha indeterminada en el periodo comprendido entre noviembre de 2006 y diciembre de 2007", aseveración que carece de asidero probatorio y subraya los dichos de los médicos Cox y Pinto, quienes examinaron a la víctima el once de diciembre de dos mil siete, y el cinco de marzo de dos mil ocho, respectivamente, y precisan que presentaba se- 
ñales de haber tenido relaciones sexuales no recientes, sin especificar datas precisas.

También se plantea la deficiente fundamentación acerca de la participación del encausado, que se refleja en el motivo $10^{\circ}$ del veredicto condenatorio, en el cual se explica que la ofendida sindicó a tres autores diferentes, pero el edicto no pormenorizó la prueba en que se asienta el cargo, limitándose a efectuar un desglose genérico. A continuación, se detalla el contradictorio relato de la ofendida, del cual se concluye que proporcionó tres versiones distintas pues denuncia a su padre, pero después, a un pololo llamado Juan, y finalmente, a su tío Leonel, lo que le resta total validez a su testimonio e introduce una duda razonable sobre la real participación del encartado en los hechos averiguados.

OCTAVO: Que, como postrer asunto anexo con la motivación subsidiaria, se alega la falta de fundamentación clara, lógica y completa de todos los hechos, prejuicios que no pueden ser sostén y una tacha de oficio, lo que se produce en el motivo $15^{\circ}$, al decir que: “...los dichos de los testigos carecen de la necesaria imparcialidad por tratarse de una hija, la cónyuge y la cuñada del acusado, respectivamente, por lo que es dable suponer que quieran favorecerlo". Lo anterior significó -en opinión de la compareciente-, valorar la prueba de acuerdo a la reglas del Código de Procedimiento Penal, volviendo al sistema de tachas, en circunstancias que el artículo 309 del Código Procesal Penal eliminó los testigos inhábiles, por lo que la actuación delatada no precisa cuáles fueron las razones en cuya virtud se les restó total validez a esos atestados.

Para terminar se consigna que el nuevo sistema ordena la libertad probatoria y de valoración, con las tres limitantes del artículo 297 del Código Procesal Penal, cita al efecto los artículos $1^{\circ}, 4^{\circ}, 5^{\circ}$ y $19, \mathrm{~N}^{\circ} 3^{\circ}$, inciso quinto, de la Carta Magna, y distingue el contenido del artículo 36 del texto adjetivo, respecto de la obligación de fundamentar las resoluciones, y el 340, inciso segundo, relativo a que la convicción debe apoyarse en la prueba producida en el transcurso del litigio, procediendo luego a efectuarse un análisis de toda la prueba y su valoración crítica, pero en ningún caso construirla a partir del mero arbitrio o voluntad de quien la forma.

Se impetra en definitiva, anular la sentencia y el juicio oral, solicita que se acoja su recurso, ordenándose retrotraer la litis a la etapa procesal que en derecho corresponda, para que un tribunal no inhabilitado disponga la realización de un nuevo juicio oral, fijando día y hora al efecto.

NOVENO: Que, como cuestión previa principal, es útil dejar en claro que tal como ya ha tenido oportunidad de señalar este máximo tribunal en los ingresos $N^{o}$. 4954-08 y el $N^{o}$. 1414-09, constituye un derecho asegurado por la Constitución Política de la República, el que toda decisión de un órgano que ejerza jurisdicción debe fundarse en un proceso previo legalmente tramitado y el artículo $19, \mathrm{~N}^{\circ} 3^{\circ}$, inciso quin- 
to, le confiere al legislador la misión de definir siempre las garantías de un procedimiento racional y justo.

En torno a los tópicos que contempla el derecho del debido proceso, no hay discrepancias en aceptar que a lo menos lo constituye un conjunto de garantías que la Constitución Política de la República, los tratados internacionales ratificados por Chile y en vigor y las leyes le entregan a las partes de la relación procesal, por medio de las cuales se procura que todos puedan hacer valer sus pretensiones en los tribunales, que sean escuchados, que puedan reclamar cuando no están conformes, que se respeten los procedimientos fijados en la ley, veredictos motivados o fundados, etc.; en tanto que, por la imparcialidad del tribunal, se comprenden tres garantías individuales de que gozan las personas de cara a la organización judicial del Estado, a saber, el derecho al juez independiente, imparcial y natural, referidos principalmente a que los asuntos criminales deben ser conocidos por los tribunales señalados por la ley con anterioridad a la perpetración del hecho punible, sin que otro poder del mismo Estado pueda avocarse a esa función, y a la forma de posicionarse el juez frente al conflicto, de modo que no medie compromiso con los litigantes o el asunto, desde que en todo proceso penal aparece comprometido el interés público de la comunidad en el esclarecimiento de los sucesos y el castigo de los delitos, como también la absolución del inocente; ese interés debe ser tutelado exclusivamente por el Ministerio Público como órgano predispuesto por el Estado precisamente con ese propósito, que incluye por cierto la exclusiva y excluyente promoción de la acción penal y la carga de probar la culpabilidad del incriminado, al mismo tiempo que el tribunal debe actuar con neutralidad y objetividad, que no puede conducirlo a abandonar su posición equidistante de las partes y desinteresada sobre el objeto de la causa.

DÉCIMO: Que de lo razonado queda de relieve la restricción de cualquier iniciativa consistente en incorporar pruebas de cargo o descargo de forma oficiosa por el tribunal, que no debe confundirse con la actividad que el artículo 329 del Código Procesal Penal expresamente habilita a los jueces del tribunal oral, atinente a que sus miembros puedan formular preguntas al testigo o perito con el fin de aclarar sus dichos, toda vez que el supuesto de la norma es que la prueba testimonial o pericial respectiva, ya fue presentada por uno de los intervinientes en la controversia, sin tener en su producción ninguna injerencia el tribunal ante el cual se rinde, y por otro lado sus preguntas aclaratorias solo se producen luego de ejecutado el examen y contraexamen pertinente, potestad que, sin lugar a dudas, en los casos que se decida ejercerla, -como ya se ha tenido oportunidad de advertir, deberá serlo con la mayor prudencia posible, recordando los jueces siempre como coto, que es función exclusiva de las partes incorporar la evidencia en juicio, y mantenerse ajenos al debate adversarial entre ellas. 
UNDÉCIMO: Que, en la situación sub lite, esta Corte, luego de escuchar atentamente la prueba de audio ofrecida por la oponente y oída la intervención de la jueza Sra. María Paz González González, integrante del Tribunal Oral en lo Penal de Chillán, algunos de cuyos trozos se reprodujeron en el recurso mismo, es dable concluir de forma manifiesta que consistió -al menos respecto de la víctima y la perito Mariela Arriagada Brito- en un nuevo interrogatorio, asemejándose al examen que la ley solo franquea al Ministerio Público, al querellante particular o a la Defensoría Penal en su caso, apreciándose de su desarrollo una serie de interrogantes que comienza a formular la magistrada a la menor afectada, inquiriendo las razones que habrían generado la intervención de su profesora, luego por sus estados de ánimo, para a continuación solicitar detalles acerca de sus responsabilidades familiares asumidas en su entorno así como sobre sus integrantes.

Posteriormente procede, a partir de diversas aserciones, a obtener solo confirmaciones respecto de presupuestos que son elaborados exclusivamente por la propia juez. Peor aún, llega incluso a preguntar derechamente a la muchacha el motivo por el cual le imputó a su propio padre la autoría del hecho pesquisado, para seguir preguntando por el significado para ella del concepto violación, rematando su respuesta con un "muy bien".

En otros pasajes la advierte acerca de la trascendencia en cuanto a la dignidad y libertad de terceros, sobre lo cual declara y que no se persigue tan solo reparar su pena; en otras responde por la testigo a modo de afirmaciones que la menor no entrega, formulándolas en su lugar, haciendo caso omiso de la objeción promovida que ni siquiera resolvió como en derecho correspondía, prosiguiendo con el interrogatorio.

En orden a un tal "Juan", le pregunta derechamente y ańade, tras inquirir si tuvo con él relaciones sexuales, antes de la contestación, lo que sigue: "... aqui no corre la vergüenza Evelyn tienes que hablar no más..."; a continuación le solicita las fechas de la denuncia, incluso agrega diversas expresiones tales como: "...volvamos, tenemos claro que tu papá te habia violado, ¿no es verdad?...", ¿cómo se te ocurrió echarle la culpa a tu papá si tú tenias tanta gente a la cual echarle la culpa?, etc.

En lo que pertenece a la perito Arriagada, se repiten los vicios ya detectados con la afectada, puesto que se aprecian numerosos asertos inculpatorios o diversos presupuestos que desarrolla autónomamente la jueza Sra. González, que después son presentadas a la testigo para obtener de ella solo afirmaciones o negaciones. En un momento la testigo le señala expresamente a la jurisdicente que con la nueva información que le entrega, tocante al traslado de la víctima a la casa de su madre en condiciones precarias, aspecto que es utilizado por la profesional para reafirmar conclusiones anteriores en el sentido que la niña no tendría ganancias secundarias; y por último, la propia magistrada concluye, expresando que 
de los resultados de los tests, los antecedentes de la carpeta investigativa como la del Centro en que labora la sicóloga la llevan a deducir que es muy probable que los hechos denunciados sean ciertos, a lo que la testigo responde afirmativamente, y que es recogido en los basamentos octavo, letra d) y décimo, letra i), como fundamentos de la condena.

De lo constatado, aparece de manifiesto que la intervención reseñada no se ajustó a los supuestos del artículo 329 del Código Procesal Penal, pues no fueron dirigidas a aclarar aspectos puntuales entregados por la ofendida y la perito psicóloga Arriagada Brito, en orden a la efectividad de la agresión sexual y la eventual participación del inculpado, por lo que puede sostenerse que eso significó en los hechos la producción de prueba por parte del tribunal, dado que, como ya se dijo, ella no fue introducida por los contendientes, y la actividad desplegada por la jueza cuestionada no se ciñó precisamente a aclarar, que según el Diccionario de la Lengua Española significa "Disipar, quitar lo que ofusca la claridad o transparencia de algo", ni procedió a hacer perceptible, manifiesto, inteligible, aquellos temas ya indicados, sino que se propuso derechamente obtenerlos por sí misma, para así apoyar su decisión condenatoria, aspectos que sin duda van más allá de la claridad del examen y contraexamen de las deponentes ya individualizadas, conclusión que permite que el presente reclamo pueda prosperar.

DUODÉCIMO: Que, en abono de las formulaciones que se vienen develando, cabe precisar que la objeción de la defensa del único imputado es real, porque el tipo de interrogaciones practicadas se alejan totalmente de los términos que contiene y faculta el artículo 329 del Código Procesal Penal, incidencia que, además, aparece zanjada incorrectamente por la señora jueza oral, ya que de acuerdo al artículo 291 del estatuto recién citado, todos los fallos que se emiten en el juicio oral deben ser dictados y fundamentados verbalmente por el mismo tribunal, y no solo -como ocurrió en la especie-, por una de sus integrantes, lo que no fue debidamente corregido por el Juez Presidente, a quien en uso del artículo 292 del mismo cuerpo legal, le compete dirigir el debate, ordenando la rendición de las pruebas, exigiendo el cumplimiento de las formalidades que correspondan y moderar la discusión.

DÉCIMO TERCERO: Que esta Corte -en cuanto a la garantía constitucional del debido proceso-, como ya se anticipó, condiciona la legitimidad de la decisión jurisdiccional, desde luego a la existencia de un órgano dotado de la prerrogativa de conocer y juzgar una causa civil o criminal, en los términos del artículo 73 de la Carta Magna y, en seguida, a que el pronunciamiento sea corolario de un proceso previo, que en el sentir del constituyente, esté asegurado por reglas formales que conformen un racional y justo procedimiento e investigación, cuya regulación deberá verificarse a través de la ley, que prevea una fase indagatoria que no se aparte de las normas de actuación del Ministerio Público, de un oportuno 
conocimiento de la acción, una adecuada defensa y la producción de la prueba pertinente en las audiencias realizadas ante el Juzgado de Garantía o ante el Tribunal del Juicio Oral en lo Penal.

DECIMOCUARTO: Que las dudas del tribunal oral deben ser satisfechas por las partes, en este proceso, fiscal y/o querellante en su caso, $\mathrm{y}$ defensor. Ellos deben poner en conocimiento de los jueces todos sus argumentos y plantear los hechos de forma acabada y suficiente para que queden bien informados sobre aquello que ha sido sometido a su conocimiento, de suerte que de subsistir cualquier dificultad o de haberse verificado alguna inexactitud, el tribunal pregunta a los mismos comparecientes en la audiencia, sobre lo que le ha resultado oscuro o desconocido.

Esta fórmula de llevar adelante la audiencia, es una manifestación del principio contradictorio que rige en el nuevo sistema penal y que constituye un elemento del derecho a defensa y, asimismo, del debido proceso, por cuanto la neutralidad del tribunal se asegura y garantiza a través del veto a su iniciativa probatoria.

Es este último, también, el motivo por el cual se ha asegurado a los intervinientes el derecho a ejercer sus facultades con tiempo y con los medios adecuados. El Ministerio Público dispone de un plazo para investigar y para reunir todos los elementos necesarios para comprobar el hecho ilícito, así como la participación del delincuente e incluso, para determinar la existencia de circunstancias especiales que puedan atenuar, modificar o eximir su responsabilidad. A su turno, la defensa tiene garantizado el tiempo y los medios, como el Ministerio Público e igualmente, el derecho para acceder a todos los medios de prueba reunidos durante la indagación, con el preciso objeto de controvertirlos, refutarlos, o simplemente explicarlos. Esta defensa que ha sido circunscrita en este procedimiento a los abogados habilitados, para garantizar su experiencia, debe ser eficaz y técnica, razones todas por las cuales no se ve cuál podría ser la necesidad de dotar al tribunal, además, de atribuciones probatorias o "para mejor acierto" de lo que se somete a su conocimiento.

En este entendido, cuando el tribunal decide de propia iniciativa llevar a cabo un improcedente interrogatorio, en el que no solo excede los márgenes de lo legalmente permitido que son las preguntas aclaratorias, sino que lo que hace en realidad es suplir eventuales insuficiencias en la información lograda transmitir por el persecutor y/o de la defensa, de suerte que se entromete en el debido desarrollo del proceso, transgrede el principio de contradicción y, de paso, afecta su propia imparcialidad, y en algunos pasajes derechamente manifestando su dictamen sobre la cuestión pendiente, lo que no puede ser tolerado.

DECIMOQUINTO: Que, a mayor abundamiento, conviene recalcar que a partir del principio de "igualdad de posiciones" en el juicio, que integra la noción de "racional y justo procedimiento", la actuación de la Jueza Oral Sra. González González, implicó un favorecimiento indebido 
a la pretensión del Ministerio Público en el litigio, interviniente sobre quien recae la carga de procurarse sus elementos de prueba y presentarse con ellos a la audiencia respectiva, para que luego, producto de su examen, habiliten al tribunal adquirir, más allá de toda duda razonable, la convicción de que realmente se hubiere cometido el hecho punible materia de la acusación y que en él hubiere correspondido al encausado una participación culpable y penada por la ley.

DECIMOSEXTO: Que la igualdad de las partes es una garantía que debe proyectarse al interior del proceso penal, traduciéndose en el hecho que cualquiera que recurra a la justicia ha de ser atendido por los tribunales con arreglo a unas mismas leyes y con sujeción a un procedimiento común, igual y fijo, por lo que estamos ante una infracción de esta naturaleza cuando se sitúa a las partes a una situación de desigualdad o se impida la aplicación efectiva del principio de contradicción. Este relevante rol incumbe al tribunal oral, quien deberá velar porque se establezca un real equilibrio, sin ningún tipo de discriminaciones entre el enjuiciado y la parte acusadora, representada por el fiscal y/o querellante particular, durante el desarrollo del juicio oral.

DECIMOSÉPTIMO: Que, por consiguiente, el persecutor penal es el exclusivo motor del proceso criminal en vigencia, de manera que resulta agraviante para la igualdad de posiciones de los litigantes que el tribunal concurra a suplir o corregir deficiencias en esa actividad, sumando a su cometido de órgano jurisdiccional objetivo e imparcial, una actividad ajena al mismo, como la incorporación de oficio de información que debió ser producida legalmente en el proceso por quien soporta ese peso; y emerge una especie de "subsidio procesal" brindado por la juez en beneficio de las posiciones del Ministerio Público, conducta que resulta totalmente fuera de lugar en el contexto de estos procedimientos.

DECIMOCTAVO: Que en este escenario el hechor fue puesto en una posición desfavorable o desventajosa, afectando el debido proceso, ya que por la irregular actuación de la Jueza Oral se vio privado de la posibilidad de obtener en el ejercicio de sus derechos como interviniente -que debe estar en absoluta igualdad de posiciones frente a su oponente y por otro lado el tribunal asumir una postura de total ecuanimidad-, una decisión jurisdiccional favorable, y experimentó así, el perjuicio trascendente requerido por la nulidad procesal, con quebranto de las normas relativas a la garantía ya aludida consagrada en el artículo $19, \mathrm{~N}^{\circ} 3^{\circ}$, inciso $5^{\circ}$, de la Constitución Política de la República, entonces resulta forzoso concluir que el edicto recaído en el procedimiento irregular en análisis es nulo.

DECIMONONO: Que, como se ha analizado hasta aquí, fluye la certeza que el Tribunal Oral de Chillán, al permitir el interrogatorio de la magistrada Sra. González González, cometió una violación de las garantías constitucionales que aseguran al agente el derecho a defensa y su debido proceso, y de paso contaminó al resto del tribunal, tiñendo sus con- 
clusiones para ajustarlas a una decisión de condena obtenida por uno de sus integrantes, sin que pueda determinarse qué prueba fue de las partes y cuál fue la obtenida por el tribunal, la que en definitiva consiguió destruir la presunción de inocencia, ambigüedad que configura la causal propuesta en forma principal por el articulista de autos.

VIGESIMO: Que si bien el artículo 373, letra a), del Código Procesal Penal, exige que el atropello de derechos o garantías sea sustancial, no debe olvidarse que el establecimiento del debido proceso en la Constitución Política de la República, encuentra su correlato en el artículo 160 del Código Procesal Penal, cuando presume de derecho la existencia del perjuicio, si la anomalía ha impedido el pleno ejercicio de las garantías y de los derechos reconocidos en la Carta Magna, o en las demás leyes de la República.

VIGÉSIMO PRIMERO: Que el respeto a los derechos fundamentales y a la legitimidad del procedimiento, vértebra del proceso entero, tal como lo pone de manifiesto la propia existencia del recurso de nulidad y la extensión de sus causales. El cumplimiento de la ley y el respeto a los derechos fundamentales no conforman aquello que los jueces están llamados a apreciar libremente, sino que configuran presupuestos de legitimidad para la emisión de cualquier pronunciamiento sobre el caso sometido a su consideración.

VIGÉSIMO SEGUNDO: Que el vicio revelado por la compareciente, aparece pues revestido de la relevancia necesaria para acoger el remedio procesal, sustentado en la letra a) del artículo 373 del Código procedimental criminal, que solo es reparable por la declaración de nulidad del juicio oral y del laudo objetado, debido a que por esta única vía podrá producirse legalmente la realización de un juicio oral respetando el debido proceso, que confiera garantías a los contendientes y es menester retrotraer la causa a la etapa de celebrarse una nueva audiencia de juicio oral ante tribunal no inhabilitado que corresponda.

En virtud de lo razonado precedentemente, el tribunal no se pronunciará sobre los otros hechos constitutivos de la causal formulada, como tampoco, de la motivación de nulidad subsidiariamente instaurada, por ser innecesario.

Por estas consideraciones y visto, además, lo prevenido en los artículos $5^{\circ}$, inciso segundo, y $19, \mathrm{~N}^{\circ} 3^{\circ}$, de la Constitución Política de la República y 159, 160, 359, 372, 373, letra a), 384 y 385 del Código Procesal Penal, SE ACOGE el recurso de nulidad formalizado por la Defensora Penal Gilda Martínez Alfaro, en lo principal del libelo de fojas 18 a 30, en representación del procesado José Felizmer Rivas González, en contra de la sentencia de tres de junio de dos mil nueve, dictada por el Tribunal Oral en lo Penal de Chillán, la que aparece transcrita de fojas 1 a 17 del cuaderno respectivo, y se declara que se anula dicho fallo y el juicio oral de que es objeto bajo el RUC No 0710026300-3, RIT No 33-2009, debiendo la 
causa retrotraerse al estado de celebrarse una nueva audiencia, ante el tribunal oral en lo penal competente y no inhabilitado que corresponda.

Regístrese y devuélvase con sus agregados.

Redacción del Ministro señor Rodríguez.

Rol No 4164-09.

Pronunciado por la Segunda Sala integrada por los Ministros Sres. Nibaldo Segura P., Jaime Rodríguez E., Rubén Ballesteros C., Hugo Dolmestch U. y Carlos Künsemüller L. No firma el Ministro Sr. Dolmestch, no obstante haber estado en la vista de la causa y acuerdo del fallo, por estar en comisión de servicios.

Autorizada por la Secretaria Suplente de esta Corte Suprema doña Carola Herrera Brummer.

En Santiago, a uno de septiembre de dos mil nueve, notifiqué en Secretaría por el Estado Diario la resolución precedente.

\section{1) LA PRUEBA Y LA FUNCIÓN QUE SE LE ASIGNA EN EL ÁMBITO DE UN PROCESO PENAL aCUSATORIO-ADVERSARIAL. PAPEles DEL TRIBU- NAL Y PAPELES DE LAS PARTES}

El eje sobre el cual gira el mecanismo en que consiste el proceso es la prueba. Eso es así con independencia de si estamos en presencia de un proceso civil o penal. Y es a propósito de las decisiones que el legislador procesal debe tomar en torno a ella que determinado sistema procesal es una cosa y no otra.

La cuestión entonces pasa por preguntarse qué función cumple la prueba en un proceso, cualquiera sea este, ya que es a partir de la respuesta a esta pregunta que pueden entenderse las concretas decisiones regulatorias a través de las cuales se articula un modelo. En otras palabras, será la función que se asigne a la prueba la que marque el contenido y alcance del resto de la regulación procesal, especialmente lo que dice relación con los papeles que se reconocen al tribunal y a las partes en la determinación de los hechos.

Pues bien, como bien ha destacado Montero Aroca, desde hace tiempo se vino despachando esta pregunta con una simple frase: se trata de averiguar la verdad de los hechos ${ }^{1}$. Y lo cierto es que no se le tomaba el real peso a dicha frase, más cuando el descubrimiento de la verdad es una

1 Montero Aroca, J. (2002) La prueba en el proceso civil. Madrid: Ed. Civitas, p. 35. 
carga que resulta imposible de sobrellevar en el esquema propio de un proceso, con sus limitaciones.

Estrechamente conectado con la cuestión de la función que se reconoce a la prueba (y todas sus consecuencias) están la función que se reconoce a la jurisdicción y los principios sobre los cuales se sustenta un proceso. Respecto a la función que se reconoce a la jurisdicción, bien ha destacado Montero Aroca, existen dos concepciones básicas. Una nos dice que lo que la jurisdicción hace es la actuación del Derecho objetivo en el caso concreto. La otra, que lo que la jurisdicción hace es ser garante último de los derechos subjetivos de las personas. En el primero caso, el Estado establece un sistema legal y el juez tiene que llegar a actuar el derecho objetivo en el caso concreto tal cual lo ha concebido el legislador. En el segundo caso, los derechos se tutelarán en el ámbito que los litigantes pidan, vale decir, los litigantes sabrán lo que piden y lo que no, ellos decidirán que hechos alegan, porque de lo que se trata es de la tutela de derechos y no de la actuación del Derecho objetivo en el caso concreto. Eso, como primera cuestión.

En segundo término, como enseña Montero Aroca, cabe tener en consideración la marca que dejan los principios con los cuales se decide jugar. En efecto, cuando se habla de la función de la prueba (y la obtención de la verdad como objetivo) el tema no puede desconectarse con lo que son los principios sobre los cuales se sustenta el proceso $^{2}$. La existencia de unos determinados principios determinará el porcentaje de verdad al cual se puede aspirar. En este punto se refuerza aún más la dicotomía entre los modelos acusatorios e inquisitivos, a pesar que como se sabe ningún sistema procesal concreto corresponde exactamente a un modelo acusatorio o inquisitivo como tipo ideal ${ }^{3}$. El modelo que rige en la actualidad en nuestro país, que sin ser puro, se acerca en mayor medida al tipo acusatorio-adversarial se encuentra sostenido sobre unos principios y un sistema de derechos procesales que condicionan el tipo de verdad al que se puede llegar, por citar un ejemplo, al decir la ley que no se pueden tener en consideración en el juicio oral las pruebas que provengan de actuaciones o diligencias que hubieren sido declaradas nulas y aquellas que hubieren sido obtenidas con inobservancia de garantías fundamentales al afectarse a privacidad, la inviolabilidad del hogar y de toda forma de comunicación privada u otras garantías establecidas en consideración del imputado.

2 En este punto véase también: Alvarado Velloso, A. (2009). La prueba judicial: reflexiones criticas sobre la confirmación procesal. Santiago: Ed. Librotecnia, pp. 33 y ss.

3 LANGer, M. (2001): "La dicotomía acusatorio-inquisitivo y la importación de mecanismos procesales de la tradición jurídica anglosajona. Algunas reflexiones a partir del procedimiento abreviado". En E. Hendler (Compilador): Las garantías penales y procesales. Enfoque histórico-comparado. Buenos Aires: Editores del Puerto, pp., 243 y ss. 
Bastaría con aludir al principio de aportación de parte asumido en el Código Procesal Penal (CPP) en reemplazo del principio de investigación oficial del modelo inquisitivo dejado atrás, para constatar que los hechos afirmados por una parte y negados por la otra han de ser probados por las partes, sin que por regla se reconozcan poderes probatorios al tribunal, opción que indudablemente marca la suerte que pueda tener el descubrimiento de la verdad en el ámbito de nuestro proceso penal.

En este sentido se ha destacado por nuestra doctrina (López Masle ${ }^{4}$ ) que uno de los rasgos más característicos de nuestro proceso penal es la absoluta pasividad del tribunal, tanto durante la etapa de investigación como durante la etapa de juicio oral, lo que implica que tenga vedada la realización de actos de investigación e, incluso, la intervención en la producción de la prueba. Un sistema acusatorio-adversarial, que parte del desdoblamiento de las funciones de perseguir y de juzgar en dos órganos estatales diferentes ${ }^{5}$, no se basa en la investigación judicial de los hechos y por lo tanto no se atribuye a los tribunales la responsabilidad de procurar establecer su certeza positiva o negativa, sino que disponen que sean las partes los protagonistas de la iniciativa y del esfuerzo conducente a aquella certeza ${ }^{6}$. En un sistema acusatorio-adversarial como el recogido por el $\mathrm{CPP}$, son los intervinientes los encargados del ingreso de la evidencia al juicio. Se impone una distribución de los poderes procesales de investigación y de decisión ${ }^{7}$.

A estas opciones legislativas se suman una serie de otros principios que vienen impuestos al legislador si lo que quiere generar como producto es verdaderamente un proceso. Se trata de una serie de principios jurídico necesarios consustanciales con la idea misma de proceso, hasta el extremo de que si alguno de ellos se desvirtúa en una regulación concreta, esa regulación no da lugar realmente a un proceso ${ }^{8}$. Nos referimos especialmente a los principios de igualdad de las partes, de contradicción o audiencia y de imparcialidad, entre otros, a partir de los cuales se ha senalado que el Tribunal no tiene porque suplir o subvencionar la inoperancia del Ministerio Público (que es, bien se ha señalado, el encargado de

4 Horvitz Lennon, M. / López Masle, J. (2002). Derecho Procesal Penal Chileno. 1a Edición. Santiago: Ed. Jurídica de Chile, Tomo I, p. 42.

5 Bovino, A. (2005). Principios politicos del procedimiento penal., Buenos Aires: Editores del Puerto, pp. 37 y ss.

6 No obstante las nuevas categorías que introduce, véase: Damaska, M. (2000). Las caras de la Justicia y el Poder del Estado: Análisis comparado del proceso legal. Santiago: Editorial Jurídica de Chile, pp. 12 y ss. También: Damaska, M. (2003). Il diritto delle prove alla derive. Bolonia: Ed. Il Mulino, pp. 109 y ss.

HoRvitz / López (2004) 44.

Montero Aroca, J. (2005). Derecho Jurisdiccional I, Parte general. 14a Edición. Valencia: Ed. Tirant Lo Blanch, p. 320. 
canalizar la pretensión punitiva del Estado), mas aún considerando que la tarea de los jueces radica en juzgar y no en probar'.

En este contexto se enmarca la única intervención admitida al tribunal en el juicio oral, cual es, la problemática posibilidad de formular preguntas al testigo o perito con el fin de que aclare sus dichos, recogida en el artículo 329.4 del CPP ${ }^{10}$ : "Finalmente, los miembros del tribunal podrán formular preguntas al testigo o perito con el fin de aclarar sus dichos". La aparente claridad de la autorización legal, en no pocos casos, termina desapareciendo debido a la errada interpretación que algunos jueces dan a lo que es una pregunta aclaratoria. No se trata de obviar la existencia de esta norma, pero sí de entender que en el marco de un modelo procesal penal acusatorio-adversarial la autorización contenida en esta norma debe ser interpretada a la luz de los principios y reglas sobre los cuales se monta este modelo. Es que no puede pretenderse regular un proceso sustentado en unos determinados principios propios del modelo antes seńalado y luego llegar a consecuencias distintas de las que se derivan de la existencia de esos principios por la interpretación equivocada que se pueda efectuar de alguna norma.

\section{2) LAS PARTICULARIDAdeS De UN CASO REAL. SObRE CÓMO LOS JUECES EXCEDEN LA AUTORIZACIÓN QUE EXISTE EN EL INTERRO- GATORIO DE TESTIGOS Y PERITOS Y CÓMO LA CORTE SUPREMA DECIDE DAR A ESTA AUTORIZACIÓN UNA INTERPRETACIÓN COHE- RENTE CON EL MODELO VIGENTE.}

En el caso en comento, seguido contra una persona por su responsabilidad como autor en el delito consumado de violación de una menor, contra la sentencia dictada por el Tribunal (Tribunal oral en lo Penal de Chillán), la defensa dedujo recurso de nulidad fundado en las causales de los artículos 373 letra a) y 374 letra e) del CPP, la primera como principal, la segunda en forma subsidiaria.

En lo que se refiere a la causal invocada de modo principal (que es la que revisaremos), se denuncia una transgresión de la garantía del debido proceso constitucionalmente tutelada en el artículo $19 \mathrm{~N}^{\circ} 3$, i.5, de la Constitución Política de la República, particularmente su componente consistente en el derecho a ser juzgado por un Tribunal imparcial, el que

9 GonzÁlez, R. (2009). "La confirmación procesal desde una perspectiva republicana” en Revista de Derecho de la Universidad Católica de la Santísima Concepción, №20, Vol. 2, p. 48.

10 Sobre la historia del establecimiento de esta norma véase: Maturana, C. (2003). Reforma procesal penal. Génesis, Historia sistematizada y Concordancias. 1ªdición. Santiago: Ed. Jurídica de Chile, pp. 640-647; Pffefer Urquiaga, E. (2001). Código Procesal penal, anotado y concordado. 1a Edición. Santiago: Ed. Jurídica de Chile, pp. 329-330. 
habría sido conculcado durante el desarrollo del referido juicio oral debido al contenido y extensión que uno de los integrantes del Tribunal dio al interrogatorio aclaratorio previsto en el art. 329 i.4 del CPP.

Entre las preguntas "aclaratorias" formuladas figuran las siguientes. A la víctima: a)... y dijiste qué cosa respecto de él (el papá)... que te había hecho qué? (a lo que la menor responde que la había violado); y b)... o sea, tu dijiste que tú papá te había forzado a tener relaciones sexuales con él? (a lo que la menor responde que sí). A la perito: a) ¿Cuando se entrevistó con Ud., esta niñita ya se había retractado de su denuncia, luego me imagino yo que la entrevista siguió en ese pie, de decir... de exculpar a quien había culpado en un primer momento, sí o no?, a lo que la perito contesta que sî́. b)... y si bien le entendí, la retractación es parte de un proceso de quienes sufren estas experiencias de violentación sexual? A lo que la perito respondió afirmativamente; y c)... entonces el resultado de los test, más los antecedentes, tanto de la carpeta de investigación como la del Centro en que Ud. trabaja, ¿la llevan a concluir que es muy probable que los hechos denunciados sean ciertos? ¿Esa es su conclusión? La perito contesta que esa es su conclusión.

Es evidente que a través de este tipo de preguntas se está excediendo el campo autorizado por el legislador procesal penal, pasando a constituirse la prueba en el juicio oral en una actividad investigadora, más que verificadora. Más cuando, como se apunta en este caso, los tiempos de interrogación utilizados por la juez que interrogó superaron largamente los manejados por las partes. No se trata de que, como ha dicho De la Oliva Santos, por un viejo prejuicio negativo hacia los jueces o que, por el contrario, los jueces deban estar atados para hacer más cómoda y menos esforzada su tarea. De lo que se trata es que en un modelo como este, por una parte, los hechos son de las partes y no del Tribunal y, por otra, el Tribunal no debe ayudar a las partes de suerte que favorezca a una en detrimento de la otra, como si al tribunal le correspondiese desempeñar también el oficio de abogado. En un modelo como el asumido en nuestro país no es razonable ni coherente que los jueces se ocupen de comprobar la certeza positiva o negativa de los hechos.

En un modelo procesal penal acusatorio-adversarial la idea del juicio oral como elemento central del debido proceso se ha reclamado entre nosotros. Esta estrecha relación impone que las reglas asociadas a la prueba respeten la idea de que son las partes y no el Tribunal los que deben extraer y controlar la información que emana de los medios de prueba, en lo que nos importan en esta ocasión, de los testigos y peritos. En un modelo acusatorio-adversarial se entiende que la depuración de información es más eficaz si el protagonismo se le asigna a las partes ${ }^{11}$. En otras

11 Véase: Duce, M. / Marín, F. / Riego, C. (2008). "Reforma a los procesos civiles orales: Consideraciones desde el debido proceso y calidad de la información”. En A. Cabezón 
palabras, la calidad de la información será mayor si se permite que todas las versiones que contengan información pueden ser objeto de un control de calidad que esté principalmente a cargo de la parte a quien esa información perjudica ${ }^{12}$. La experiencia ha demostrado que son las propias partes quienes se encuentran en mejores condiciones que nadie para lograr un resultado de certeza sobre los hechos relevantes para la decisión jurisdiccional que se requiera en cada caso. De allí la razonabilidad de que sean las partes los protagonistas de la iniciativa y del esfuerzo probatorio, cautelando la neutralidad que debe mantener el Tribunal, que debe evitar inclinarse por alguna de las partes.

El fallo de la Corte Suprema, que acoge la nulidad impetrada, anulando el fallo y el juicio oral disponiendo que la causa se retrotraiga al estado de celebrarse una nueva audiencia, ante el tribunal oral en lo penal competente y no inhabilitado que corresponda, reafirma el derecho a un Tribunal imparcial como integrante de la garantía del debido proceso y que el interés público de la comunidad en el esclarecimiento de los hechos y el castigo de los delitos debe ser tutelado, en nuestro sistema, exclusivamente por el Ministerio Público como órgano previsto precisamente con ese propósito, "que incluye por cierto la exclusiva y excluyente promoción de la acción penal y la carga de probar la culpabilidad del incriminado, al mismo tiempo que el Tribunal debe actuar con neutralidad y objetividad, que no puede conducirlo a abandonar su posición equidistante de las partes y desinteresada sobre el objeto de la causa”.

Respecto de la actividad que el artículo 329.4 CPP expresamente habilita a los jueces del Tribunal Oral señala la Corte que "en los casos en que se decida a ejercerla deberá serlo con la mayor prudencia posible, recordando los jueces siempre como coto, que es función exclusiva de las partes incorporar la evidencia en juicio, y mantenerse ajenos al debate adversarial entre ellas". Pues bien, se señala en el fallo que en cuanto al interrogatorio judicial efectuado a la víctima y perito se está en presencia, en realidad, de un nuevo interrogatorio que excediendo la autorización legal se termina asemejando más al examen que corresponde a las partes.

Entre lo que Corte escuchó antes de resolver este recurso se aprecian "una serie de interrogantes que comienza a formular la magistrada a la menor afectada, inquiriendo las razones que habrían generado la inter-

(Coordinador): Justicia civil: Perspectiva para una reforma en América Latina. Santiago: Centro de estudios de Justicia de las Américas, CEJA, pp. 48 y ss.

12 Duce/Marín/Riego (2008) 50. El Tribunal "recibirá en el juicio información cuya calidad no tiene cómo corroborar (el juez no investiga) y entonces lo que hará es permitir que la parte a quien esa información perjudica desarrolle sus mejores esfuerzos con el fin de mostrarle las falencias, distorsiones o errores que esas versiones contienen. Este esfuerzo de la contraparte no solo servirá para revelar los puntos débiles de cada versión, sino que también resultará clave para afianzar aquella información o versiones que efectivamente son confiables y que debieran tener un peso importante en la formación de la convicción del Tribunal". 
vención de su profesora, luego por sus estados de ánimo, para a continuación solicitar detalles acerca de sus responsabilidades familiares asumidas en su entorno así como sobre sus integrantes". "Posteriormente procede, a partir de diversas aserciones, a obtener solo confirmaciones respecto de presupuestos que son elaborados exclusivamente por la propia jueza... llega incluso a preguntar derechamente a la muchacha el motivo por el cual le imputó a su propio padre la autoría del hecho pesquisado, para seguir preguntando por el significado para ella del concepto violación, rematando su respuesta con un muy bien". En otros pasajes "responde por la testigo a modo de afirmaciones que la menor no entrega, formulándolas en su lugar, haciendo caso omiso de la objeción promovida... prosiguiendo con el interrogatorio". "En orden a un tal Juan, le pregunta derechamente y añade, tras inquirir si tuvo con él relaciones sexuales, antes de la contestación, lo que sigue: ....aquí no corre la vergüenza Evelyn tienes que hablar no más...; a continuación le solicita las fechas de la denuncia, incluso agrega diversas expresiones tales como: ...volvamos, tenemos claro que tu papá te había violado, ¿no es verdad?..., ¿cómo se te ocurrió echarle la culpa a tu papá si tú tenías tanta gente a la cual echarle la culpa?, etc.”.

En lo que se relaciona con el interrogatorio a la perito Arriagada, señala la Corte, se repiten los vicios ya detectados con la víctima, y se aprecian numerosos asertos inculpatorios o diversos presupuestos que desarrolla autónomamente la jueza que interroga, que después son presentadas a la testigo para obtener de ella solo afirmaciones o negaciones. Recoge el fallo de la Corte: "En un momento la testigo le seńala expresamente a la jurisdicente que con la nueva información que le entrega, tocante al traslado de la víctima a la casa de su madre en condiciones precarias, aspecto que es utilizado por la profesional para reafirmar conclusiones anteriores en el sentido que la niña no tendría ganancias secundarias; y por último, la propia magistrada concluye, expresando que de los resultados de los tests, los antecedentes de la carpeta investigativa como la del Centro en que labora la sicóloga la llevan a deducir que es muy probable que los hechos denunciados sean ciertos, a lo que la testigo responde afirmativamente, y que es recogido en los basamentos octavo, letra d) y décimo, letra i), como fundamentos de la condena”.

Para la Corte el interrogatorio realizado por la jueza significó, en los hechos, la producción de prueba por parte del Tribunal, lo que va contra el sistema procesal penal vigente y algunos de los contenidos más caros de la garantía del debido proceso, principalmente la imparcialidad del Tribunal, la contradicción y la igualdad de armas. La actividad de la jueza no se circunscribió precisamente a aclarar (que es lo autorizado por la Ley), sino que fue mucho más allá, incorporando nueva prueba no generada ni introducida por las partes. Cita el fallo de la Corte el significado que según el Diccionario de la Lengua Española tiene asignado el término "acla- 
rar": "Disipar, quitar lo que ofusca la claridad o transparencia de algo". Concluye la Corte señalando que "cuando el tribunal decide de propia iniciativa llevar a cabo un improcedente interrogatorio, en el que no solo excede los márgenes de lo legalmente permitido que son las preguntas aclaratorias, sino que lo que hace en realidad es suplir eventuales insuficiencias en la información lograda transmitir por el persecutor y/o de la defensa, de suerte que se entromete en el debido desarrollo del proceso, transgrede el principio de contradicción y, de paso, afecta su propia imparcialidad, y en algunos pasajes derechamente manifestando su dictamen sobre la cuestión pendiente, lo que no puede ser tolerado"13.

Además de lo anterior, el fallo de la Corte Suprema se hace cargo de una cuestión que en terreno de la práctica forense desde hace tiempo viene generando problemas, derivados justamente del difícil encaje que en el modelo procesal penal tiene este interrogatorio judicial con finalidades aclaratorias. Nos referimos a la reiterada discusión en torno a si frente una interrogación judicial que excede los límites del art. 329.4 CPP es procedente o no una objeción. La respuesta, en teoría, se decía afirmativa. Pero la práctica judicial, bien se puntualizaba, decía otra cosa ${ }^{14}$.

Se ocupa del tema la Corte en el considerando duodécimo señalando: "Que, en abono de las formulaciones que se vienen develando, cabe precisar que la objeción de la defensa del único imputado es real, porque el tipo de interrogaciones practicadas se alejan totalmente de los términos que contiene y faculta el artículo 329 del Código Procesal Penal, incidencia que, además, aparece zanjada incorrectamente por la señora jueza oral, ya que de acuerdo al artículo 291 del estatuto recién citado, todos los fallos que se emiten en el juicio oral deben ser dictados y fundamentados verbalmente por el mismo tribunal, y no solo -como ocurrió en la especie-, por una de sus integrantes, lo que no fue debidamente corregido por el Juez Presidente, a quien en uso del artículo 292 del mismo cuerpo legal, le compete dirigir el debate, ordenando la rendición de las pruebas, exigiendo el cumplimiento de las formalidades que correspondan y moderar la discusión”.

13 Bien se ha señalado por la doctrina que uno podría tener dudas que dicho juez mantenga su imparcialidad a la hora de fallar, ya que si uno desea examinar a un testigo sobre el fondo del caso y pretende hacerlo con efectividad, resulta ineludible hacerlo desde una particular posición dentro del caso (natural para las partes, no para el juez), con la que inevitablemente uno se compromete. Baytelman, A. (2000). "El juicio oral". En A. Carocca, y otros: Nuevo Proceso Penal. Santiago: Ed. Jurídica ConoSur, p. 233.

14 Pacheco Bastidas, A. (2003) "Reflexiones sobre la facultad que otorga el artículo 329 del CPP para que los miembros del Tribunal Oral en lo Penal puedan dirigir preguntas aclaratorias a los testigos y peritos” en Revista Procesal Penal N ${ }^{\circ} 15$, p. 22. 
Es decir, frente a la tesis tradicional de los Tribunales de estimar que sus preguntas no son objetables (solo lo serían las preguntas formuladas por las partes litigantes y ellos no lo son, se precisa), este fallo de la Corte Suprema hace expresamente procedente la objeción (en rigor: incidencia) en contra de este tipo de preguntas e impone al Tribunal la obligación de resolverla, todo ello en la dirección de preparar el recurso de nulidad que se pueda intentar posteriormente de cara a lo dispuesto por el artículo 377.1 del $\mathrm{CPP}^{15}$. En otras palabras, si el planteamiento de la objeción no alcanza para impedir que se incorpore prueba o información inadmisible al juicio, al menos deberá servir para que se entienda debidamente preparado el recurso de nulidad que se intente luego contra la sentencia. En adelante, por tanto, las objeciones deben ser entendidas como una herramienta para limitar no solo a aquella parte que no respeta los límites del proceso y coartarlo en esa actuación incorrecta, sino que también posible de utilizar frente a una interrogación judicial que no se ajusta a las exigencias y límites de la Ley.

No podemos sino compartir estas consideraciones de la Corte $\mathrm{Su}$ prema, más aún si se tienen presente que la prueba por excelencia en el juicio oral está constituida por el testimonio ${ }^{16}$. En un modelo acusatorioadversarial como el nuestro los jueces deben evitar toda participación en la investigación de los hechos o en la formación de los elementos de convicción. Son las partes las que deben suministrar al Tribunal razones y pruebas. Como se ha dicho bien ${ }^{17}$, son las partes las que deben esmerarse en procurar al Tribunal los medios necesarios para que se les dé la razón. De esta forma el interés de las partes se convierte en carga, en el sentido de que si la parte no ofrece una prueba o una razón, debe soportar el dańo de que el juez no puede tomarla en cuenta. Ese principio, el de la carga de la prueba, tiene la ventaja de imprimir el máximo de energía a la actividad de las partes. Al permitir un interrogatorio como el que realizó la jueza en este caso se comete una violación de las garantías constitucionales que aseguran el derecho a defensa y su debido proceso, "y de paso contaminó al resto del tribunal, tiñendo sus conclusiones para ajustarlas a una decisión de condena obtenida por uno de sus integrantes, sin que pueda determinarse qué prueba fue de las partes y cuál fue la obtenida por el tribunal, la que en definitiva consiguió destruir la presunción de inocencia”.

15 "Si la infracción invocada como motivo del recurso se refiriere a una ley que regulare el procedimiento, el recurso solo será admisible cuando quien lo entablare hubiere reclamado oportunamente del vicio o defecto".

16 Cerda San martín, R. (2007). Nueva visión del juicio oral penal. Santiago: Ed. Librotecnia, 2007, p. 283.

17 Carnelutti, F. (2004). Cómo se hace un proceso. Traducción de Santiago Sentis Melendo. $4^{\mathrm{a}}$ Reimpresión de la 2a Edición. Bogotá: Ed. Temis, p. 82. 


\section{3) LO QUE PUDO ABORDARSE CON UNA MAYOR PRECISIÓN. LA DE- TERMINACIÓN DE CUÁNDO UNA PREGUNTA RESULTA SER, EN ES- TRICTO SENTIDO, ACLARATORIA, Y POR TANTO, RESPETUOSA DE LA AUTORIZACIÓN RECOGIDA EN EL ARTÍCULO 329.4 CPP}

Esta sentencia de la Corte Suprema tiene la virtud de poner de relieve la incompatibilidad de un interrogatorio judicial como el transcrito con un modelo procesal acusatorio-adversarial. Asimismo, describe con acierto los problemas que apareja de cara al adecuado respeto de los contenidos de la garantía fundamental del debido proceso en el ámbito de un juicio oral en donde los llamados a incorporar y controlar la prueba son las partes ${ }^{18}$. Añadidamente, hace procedente la objeción en contra de este tipo de preguntas e impone al Tribunal la obligación resolverla. Todas estas prevenciones, como señala la propia sentencia, aconsejan hacer uso de esta posibilidad con prudencia, limitándola a una pura aclaración que no consista en la incorporación de prueba nueva que no haya sido comprendida en la declaración que se quiere aclarar.

No poner atajo oportunamente a actuaciones judiciales que no se avienen con el modelo y no respetan las limitaciones impuestas por el legislador a las facultades y poderes en materia probatoria puede significar la tolerancia y proliferación de las mismas, poniendo en peligro la integridad del modelo que democráticamente se dio nuestro país hace unos años. La norma del artículo 329.4 no debe convertirse en una amenaza a esta integridad si se logra interpretar de forma coherente y respetuosa con los principios y reglas sobre los cuales se sustenta nuestro modelo procesal penal como lo trata de hacer la sentencia de la Corte Suprema que hemos traído a colación.

Teniendo claro lo antes señalado y que es labor de las partes extraer las declaraciones de los testigos y peritos, debiendo el tribunal mantener un papel de tercero imparcial, respetuoso de la igualdad de armas y el principio de contradictoriedad, la tarea pendiente de abordar es definir con mayor claridad cuando estamos frente a una pregunta aclaratoria. La sentencia de la Corte Suprema, se concentra en destacar que el interrogatorio llevado a cabo por la jueza del Tribunal Oral de Chillán excedió la autorización legal, pero sigue sin determinar cuándo una pregunta es aclaratoria.

La referencia al Diccionario de la Lengua Española que se hace en el fallo tampoco resulta suficiente. Bien se ha destacado que el término "aclarar" puede dar para mucho, razón por la cual no sirve, por sí solo,

18 Opinión consolidada es que en un sistema acusatorio-adversarial o contradictorio como el implementado por nuestro CPP, son los intervinientes los encargados del ingreso y control de la evidencia al juicio. 
para iluminar la interpretación de la norma ${ }^{19}$. Debe echarse mano, necesariamente, a los principios procesales, e interpretar la norma de modo tal de no autorizar actuaciones judiciales que atenten contra las bases sobre las cuales se ha montado el modelo, especialmente la imparcialidad que debe mantener el juzgador durante el juicio ${ }^{20}$.

Una fórmula que podría entenderse ajustada al modelo es aquella que partiendo del carácter excepcional de esta actuación judicial, define como aclaratoria aquella interrogación neutra que no busca una respuesta que adicione elementos a la declaración del testigo o perito, sino que persigue solamente permitir al juez entender elementos y expresiones que forman parte de esa declaración ${ }^{21}$. Bien se sabe que muchas de las personas que declaran en un juicio penal tienen su propio lenguaje. Lo propio ocurre con el lenguaje técnico de los peritos que puede resultar, en ocasiones, necesario de aclarar por parte de algún juez ${ }^{22}$.

Otra fórmula, también compatible con los límites del art. 329.4 CPP, parte de la base de establecer una clara diferencias entre aclarar y adicionar $^{23}$. Una aclaración dice relación con la clarificación de una información ya entregada por la fuente de prueba, llámese testigo o perito. Por ejemplo: Sr. testigo, no me queda claro algo, Ud. dijo que había llegado temprano alrededor del medio día: ¿Eso entonces significa que Ud. llegó aproximadamente a las 12:00 horas? Esta pregunta sería, efectivamente, aclaratoria, ya que tiene por objetivo aclarar el concepto de temprano y fija el medio día. No ocurre lo mismo en este otro escenario: Sr. testigo, cuando llegó Ud. dijo que estaba el imputado y don Juan Pérez, pero además quiero que me aclare si estaba don Pedro Prado y don Juan González. El testigo nunca señaló que estaban junto al imputado don Pedro Prado y don Juan González. Esa es, por tanto, una interrogación que excede los límites permitidos por la Ley y el modelo, por más que se intente disfrazar como pregunta aclaratoria. Lo que se persigue en

19 "Por ejemplo, para dar transparencia, iluminar, alumbrar, disipar o quitar lo que ofusca, es perfectamente posible la incorporación de un nuevo elemento que aclara la cuestión y nos hace verla de otra manera (clara, prístina, nítida; antes oscura, confusa, etc.). Esta visión aclarada de la cuestión puede resultar, muchas veces, una nueva cuestión”. Véase: PACHeco (2003) 16.

20 Montero (2005). El valor de los principios, se dice, no es solo teórico, sino que tiene repercusiones prácticas. Una de ellas es "servir de elemento auxiliar de la interpretación".

21 Pacheco (2003) 20.

22 Como ejemplifica Pacheco: Un testigo declara que el acusado le dio un "tunazo" a la víctima; un perito declara que la imputada presenta el "Síndrome de Blanca Nieves". Pacheco (2003) 20.

23 Ilustrativos ejemplos de Pelayo Vial. Bien señala en su libro que el CPP consagra un verdadero proceso, en donde bajo las reglas que derivan del modelo, el protagonismo de las partes (y no de los jueces) y el contraexamen se debe dar confiabilidad a la prueba y establecer la veracidad de lo declarado por los testigos y peritos. Vial Campos, P. (2006). Técnicas y fundamentos del contraexamen en el proceso penal chileno. Santiago: Ed. Librotecnia, p. 11. 
este segundo caso no es aclarar sino que una información adicional, no incorporada antes.

El riesgo de no mantener un rol pasivo de los jueces en el ingreso de la prueba, dice relación con el vaciamiento de contenido del deber de imparcialidad ${ }^{24}$, además de la afectación de principios tan fundamentales como la igualdad de armas y contradictorio ${ }^{25}$. Es que cada una de las partes va generando hipótesis al momento en que se desarrolla el juicio; es natural al rol de las partes que están litigando. No es natural, sin embargo, al papel del juzgador, que debe decidir en definitiva, y que desde luego no deben realizar actividades para confirmar o descartar hipótesis que deben permanecer en su fuero interno durante el desarrollo del juicio. En otras palabras, se ha sentenciado, los jueces deben presenciar y escuchar toda la prueba sin subvencionar a ninguna de las partes, y luego decidir con el material probatorio recibido.

Ir más allá, con la excusa de querer descubrir la verdad de los hechos, es no entender que el esquema de trabajo bajo el cual se desarrolla un modelo procesal acusatorio-adversarial apuesta porque la decisión judicial se ajuste lo más posible a la verdad y la Justicia, pero sobre la base del protagonismo de las partes, la pasividad del Tribunal y el respeto absoluto a unos principios que se entienden tan relevantes como el objetivo final ${ }^{26}$, aquellos sin los cuales no es siquiera concebible un proceso que se ajuste al estándar impuesto tanto en nuestra Constitución Política como en los Tratados Internacionales de Derechos Humanos.

Llámesele garantismo procesal o como se prefiera. De lo que se trata es de cerrar la puerta a actuaciones que son propias un modelo procesal inquisitivo, con un rol activo de los jueces, ya superado en materia procesal penal. Como diría Alvarado Velloso, frente al "decisionismo judicial" 27 que no respeta la garantía fundamental del debido proceso, amparado en una difusa meta justiciera, se instala la garantía constitu-

24 La propia Corte Suprema ha seguido profundizando en el enfoque no solo subjetivo que cabe dar a la imparcialidad del Tribunal, cuidando también las apariencias objetivas o externas que puedan poseer la capacidad de poner en duda la imparcialidad del Tribunal. Véase: Sentencia CS causa rol No4181-2009, de 19 de noviembre de 2009. En el plano dogmático, entre nosotros, véase un reciente trabajo sobre el tema: Etcheverría Ramírez, G. (2010). "Imparcialidad del Tribunal Oral en lo Penal: Tras la conquista de la garantía" en Revista de Derecho $\mathrm{N}^{\circ} 1$, Vol. XXIII, pp. 269 y ss.

25 Por eso es que en Estados Unidos, como ha destacado Damaska, las Reglas Federales de Evidencia (661 y ss.) que autorizan al juez a preguntar e incluso llamar testigos no se utilizan por entenderse extrañas al sistema y peligrosas para la imparcialidad del tribunal.

26 Otra sentencia relevante de la CS, sostiene que es objetable todo ingreso de información al juicio que debió ser producida legalmente en el proceso por el Ministerio Público. El fallo se refiere a la incorporación por parte del juez de antecedentes que no fueron hechos valer por el ente persecutor, en el marco de un procedimiento simplificado. Véase: Sentencia CS causa rol No5658-2009, de 3 de noviembre de 2009.

27 Alvarado Velloso, A. (2003). El debido proceso de la garantía constitucional. Rosario: Ed. Zeus, pp. 205 y ss. 
cional del debido proceso y la figura del tribunal imparcial y un método acusatorio en d0nde las partes, en pie de igualdad jurídica, discuten sobre sus pretensiones ante un tercero imparcial que actúa al efecto en carácter de autoridad, dirigiendo y regulando el debate para, llegado el caso, sentenciar el asunto.

Cuando se entiende bien la idea de proceso, cuando se entienden bien los roles de las partes y el rol que corresponde al juez, cuando se entiende bien la finalidad de la actividad probatoria, la interpretación y aplicación de normas como la recogida en el art. 329.4 del CPP puede resultar más pacífica. Cuando no se comprende el cambio en que consiste el tránsito entre un modelo fundamentalmente inquisitivo a otro fundamentalmente acusatorio-adversarial es necesario que el sistema se proteja con sentencias como la de la Corte Suprema que hemos considerado oportuno comentar en esta ocasión.

\section{BIBLIOGRAFÍA}

- Alvarado Velloso, A. (2009). La prueba judicial: reflexiones criticas sobre la confirmación procesal. Santiago: Ed. Librotecnia.

- Alvarado Velloso, A. (2003). El debido proceso de la garantía constitucional. Rosario: Ed. Zeus.

- Baytelman, A. (2000). "El juicio oral". En A. Carocca, y otros: Nuevo Proceso Penal. Santiago: Ed. Jurídica ConoSur.

- Bovino, A. (2005). Principios politicos del procedimiento penal, Buenos Aires: Editores del Puerto.

- Carnelutti, F. (2004). Cómo se hace un proceso. Traducción de Santiago Sentis Melendo. 4a Reimpresión de la 2a Edición. Bogotá: Ed. Temis.

- Cerda San martín, R. (2007). Nueva visión del juicio oral penal. Santiago: Ed. Librotecnia, 2007.

- Damaska, M. (2000). Las caras de la Justicia y el Poder del Estado: Análisis comparado del proceso legal. Santiago: Editorial Jurídica de Chile.

- Damaska, M. (2003). Il diritto delle prove alla derive. Bolonia: Ed. Il Mulino.

- GonzÁlez, R. (2009). "La confirmación procesal desde una perspectiva republicana" en Revista de Derecho de la Universidad Católica de la Santísima Concepción, N²0, Vol. 2.

- Duce, M. / Marín, F. / Riego, C. (2008). "Reforma a los procesos civiles orales: Consideraciones desde el debido proceso y calidad de la información”. En A. Cabezón (Coordinador): Justicia civil: Perspectiva para una reforma en América Latina. Santiago: Centro de estudios de Justicia de las Américas, CEJA. 
- Etcheverría Ramírez, G. (2010). “Imparcialidad del Tribunal Oral en lo Penal: Tras la conquista de la garantía" en Revista de Derecho $\mathrm{N}^{\circ} 1$, Vol. XXIII.

- Horvitz Lennon, M. / López Masle, J. (2002). Derecho Procesal Penal Chileno. 1a Edición. Santiago: Ed. Jurídica de Chile, Tomo I.

- Langer, M. (2001): "La dicotomía acusatorio-inquisitivo y la importación de mecanismos procesales de la tradición jurídica anglosajona. Algunas reflexiones a partir del procedimiento abreviado”. En E. Hendler (Compilador): Las garantías penales y procesales. Enfoque histórico-comparado. Buenos Aires: Editores del Puerto.

- Maturana, C. (2003). Reforma procesal penal. Génesis, Historia sistematizada y Concordancias. $1^{\text {a }}$ Edición. Santiago: Ed. Jurídica de Chile.

- Montero Aroca, J. (2002). La prueba en el proceso civil. Madrid: Ed. Civitas.

- Montero Aroca, J. (2005). Derecho Jurisdiccional I, Parte general. $14^{\text {a }}$ Edición. Valencia: Ed. Tirant lo Blanch.

- Pacheco Bastidas, A. (2003) "Reflexiones sobre la facultad que otorga el artículo 329 del CPP para que los miembros del Tribunal Oral en lo Penal puedan dirigir preguntas aclaratorias a los testigos y peritos" en Revista Procesal Penal N ${ }^{\circ} 15$.

- Pffefer Urquiaga, E. (2001). Código Procesal penal, anotado y concordado. $1^{\text {a }}$ Edición. Santiago: Ed. Jurídica de Chile.

- Vial Campos, P. (2006). Técnicas y fundamentos del contraexamen en el proceso penal chileno. Santiago: Ed. Librotecnia. 